\title{
Assessing atopic disease in children two to six years old: reliability of a revised questionnaire
}

\author{
*Torbjørn Øiena, Ola Storrøa, Roar Johnsen ${ }^{b}$ \\ a Research Fellow, Department of Public Health and General Practice, Faculty of Medicine, Norwegian University of Science and \\ Technology (NTNU), Trondheim, Norway \\ ${ }^{b}$ Professor, Department of Public Health and General Practice, Faculty of M edicine, NTNU, Trondheim
}

Received 18th December 2006; revised version received 24th April 2007; accepted 25th January 2008; online 16 th March 2008

\begin{abstract}
Background: Primary intervention - reducing second hand smoking (SHS), indoor dampness, and increased intake of omega-3-fatty acids - for allergic diseases such as asthma, rhinoconjunctivitis, and eczema/dermatitis in children wasstarted in Trondheim in 2002. To our knowledge, no validated or reliable questionnaires for the study age groups were available,

Aims: To test the reliability of a revised questionnaire for studying atopic disease in children two to six years old in Trondheim.

Methods: Seventy-seven families were invited to fill in a questionnaire adapted from the ISAAC protocol which was made appropriate for the age group studied. Completed questionnaires and information from medical records were compared, and the agreement was analysed by Kappa statistics and proportional agreement.

Results: Agreement was excellent for questions reporting current information such as doctor-diagnosed asthma ( $\kappa=0.88$ ), whether or not the child had had an allergy test $(\kappa=0.82)$, and use of antibiotiç $(\kappa=0.81)$. The agreement was good for questions concerning doctor or hospital treatment for asthma $(\kappa=0.59)$, medication for asthma $(\kappa=0.58)$, symptoms of eczema $(\kappa=0.56)$, medication for allergic disease $(\kappa=0.45)$, and past infections $(\kappa=0.53)$.

Conclusion: Questions on asthma diagnosis, attergy testing, and use of antibiotics were reliable. Questions on medical treatment for eczema, allergic rhinoconjunctivitis and infections weréless reliable, representing a potential source of information bias and possible misclassification.

(c) 2008 General Practice Airways Group. All rights reserved.

T Øien, et al. Prim Care RespJ 2008; 17(3): 164-168.

doi:10.3132/pcrj.2008.00023
\end{abstract}

Keyw ords questionnaires, reliability, primary prevention, asthma, allergy, allergic rhinitis, allergic conjunctivitis, eczema

\section{Introduction}

The municipality of Trondheim, Norway, was chosen for a large study on the effectiveness of primary prevention for asthma, rhinoconjunctivitis, and eczema/dermatitis, in children from birth up to two years of age - the Prevention of Allergy among Children in Trondheim study (PACT). ${ }^{1}$ The interventions included reducing second-hand smoking (SHS) and indoor dampness, and increasing intake of omega-3-fatty acids.

After searching on Medline and the Cochrane database, no validated or reliable questionnaires for assessing the prevalence of risk factors and the incidence of asthma, rhinoconjunctivitis and eczema/dermatitis in children aged two to six years old were found. Most of the existing questionnaires were variations of those used in the ISAAC study ${ }^{2}$ for use in older children.

To evaluate the effect of the intervention, existing ISAAC questionnaires had to be revised for the study age group. Three main requirements were specified for the development of the questionnaire: first, the extent of the questionnaire should be sufficient to estimate symptoms and complaints consistent with asthma, rhinoconjunctivitis, and eczema/dermatitis, and to

\footnotetext{
* Corresponding author: Norwegian University of Science and Technology (NTNU), N-7489 Trondheim, Norway.

Tel: +4773598876 Fax: +4773597577 E-mail: torbjorn.oien@ntnu.no
} 
describe use of health care services and treatment for these diseases; second, the questionnaire should be possible to complete during a maternal and child health centre consultation of average duration (i.e. 30 minutes); and third, it should be designed to obtain satisfactory validity.

The aim of this study therefore was to test the reliability of a new questionnaire used in the PACT study for studying symptoms of asthma, rhinoconjunctivitis, and eczema/ dermatitis among children two to six years old.

\section{Methods}

A collaborative group of primary care physicians and maternity and child healthcare nurses was established to develop the questionnaire. A modified focus group evaluation - which included a group of 12 parents (six couples) - was then performed to assess whether or not the requirements were met, and to study the feasibility of the questionnaire. Comments on the extent and comprehensibility of the questionnaire were collected from this group.

After development, the questionnaire consisted of 26 questions on symptoms of allergic diseases, and two questions on infectious diseases and hospitalisation in the first two years of life. Ten of the questions revealed information that could be expected to be found in medical records. The reliability was assessed by evaluating the agreement between answers to these ten questions and information obtained from various medical records in primary health care, paediatric practices and in hospitals.

The study group consisted of two populations of children in Trondheim. The first was a random group of parents of 47 children with few incident cases fpilot study of the questionnaire). To increase the number of incident cases a second group of parents of 30 children was randomly selected among those with a positive answer to questions on doctor-diagnosed asthma and/or parental-reported eczema from the control group in the PACT study.

We obtained written consent from 38 parents (of 47 invited) in the pilot study, and results from these are used in the analysis. A brief feasibility and time consumption questionnaire was completed by 36 participants in the pilot study. For both groups, information was requested from their primary physician, together with information in medical records from the municipality emergency centre, hospital admissions, maternity ward centres and paediatricians in Trondheim. For 66 of the 77 (86\%) participants the information was sufficient to complete all 10 items (see Table 1).

The questionnaire was evaluated by comparing the answers given in the questionnaires with the information obtained from the children's medical records. Two investigators assessed all information in the health records, and then both completed a registration form for each participant. When doubt or disagreement in interpreting the medical records was experienced, consensus between the investigators was obtained through discussion. The data collection was finished in 2001.

For statistical analysis, we used SPSS for $W$ indow $S^{\circledR}$ ver. 12.0 and Excel. To analyse the agreement between answers given in the questionnaire and information obtained from different medical records, estimated observed agreement, proportional agreement, and Kappa statistics with 95\% confidepce intervals $(\mathrm{Cl})$ were used..$^{3,4}$

The study was approved by the Regional Committee for Medicat Research Ethics and the establishment of patient Register was licensed by the Norwegian Data Inspectorate.

\section{Results}

\section{Feasibility and time consumption}

The mean age of the 36 children in the feasibility study was 33.4 months, with a range of 24-66 months. Median time spent completing the questionnaire was 6.5 minutes (range 1-15). Eighteen of 36 participants managed to complete the form whilst waiting for the maternity centre consultation; the rest completed it after the consultation.

Modified focus group evaluation

The modified focus group evaluation - which included six parental couples who were invited to comment on the design

Table 1. Patient numbers and participation.

\begin{tabular}{lcccc} 
Number of participants invited & $\begin{array}{c}\text { Questionnaires in } \\
\text { reliability } \\
\text { study }\end{array}$ & $\begin{array}{c}\text { Feasibility and } \\
\text { time consumption } \\
\text { questionnaire }\end{array}$ & $\begin{array}{c}\text { Modified focus } \\
\text { group } \\
\text { evaluation }\end{array}$ & $\begin{array}{c}\text { Written consent } \\
\text { and information } \\
\text { obtained }\end{array}$ \\
\hline $\begin{array}{l}\text { Pilot study } \\
47 \text { children invited at maternity care centres }\end{array}$ & 38 & 36 children & 6 parents & \\
\hline $\begin{array}{l}\text { Control group PACT } \\
30 \text { children reported having asthma and/or } \\
\text { eczema in questionnaire }\end{array}$ & 28 & & & \\
\end{tabular}


Table 2. Agreement between 10 questions from the questionnaire, and medical record data.

\begin{tabular}{|c|c|c|c|c|c|c|}
\hline Questionnaire & Obtained from records & $\mathrm{N}$ & $\begin{array}{c}\text { Kappa } \\
(\mathrm{Cl} 95 \%)\end{array}$ & OA & $\mathrm{n}$ & $\begin{array}{c}\mathrm{PA} \\
\text { yes/no }\end{array}$ \\
\hline $\begin{array}{l}\text { 1. Has your child ever been diagnosed } \\
\text { as having asthma by a doctor? }\end{array}$ & $\begin{array}{c}\text { Asthma/wheezing } \\
>2 \text { obstructive episodes }\end{array}$ & 53 & $\begin{array}{c}0.88 \\
(0.76-1.0)\end{array}$ & $\begin{array}{c}0.94 \\
(50 / 53)\end{array}$ & 23 & $0.93 / 0.95$ \\
\hline $\begin{array}{l}\text { 2. Has your child ever been treated by } \\
\text { doctor or hospitalised for asthma? }\end{array}$ & Treatment for asthma & 31 & $\begin{array}{c}0.59 \\
(0.31-0.88)\end{array}$ & $\begin{array}{c}0.80 \\
(25 / 31)\end{array}$ & 18 & $0.84 / 0.75$ \\
\hline $\begin{array}{l}\text { 3. In the past } 12 \text { months, has your child } \\
\text { used any medicines, pills, puffers or other } \\
\text { medication for wheezing or asthma? }\end{array}$ & $\begin{array}{l}\text { Asthma medication } \\
\text { prescribed }\end{array}$ & 31 & $\begin{array}{c}0.58 \\
(0.28-0.88)\end{array}$ & $\begin{array}{c}0.80 \\
(25 / 31)\end{array}$ & 19 & $0.85 / 0.73$ \\
\hline $\begin{array}{l}\text { 4. Has your child ever had an itchy rash } \\
\text { coming and going for at least } 6 \text { months? }\end{array}$ & Eczema & 64 & $\begin{array}{c}0.56 \\
(0.38-0.75)\end{array}$ & $\begin{array}{c}0.78 \\
50 / 64\end{array}$ & 32 & $0.72 / 0.41$ \\
\hline $\begin{array}{l}\text { 5. In the past } 12 \text { months, has your child } \\
\text { used any medicines, ointments, creams, } \\
\text { pills or other medications for an itchy } \\
\text { skin rash or eczema? }\end{array}$ & $\begin{array}{l}\text { Eczema medication } \\
\text { prescribed }\end{array}$ & 65 & $\begin{array}{c}0.33 \\
(0.11-0.54)\end{array}$ & $\begin{array}{c}0.71 \\
(46 / 65)\end{array}$ & 26 & $0.49 / 0.80$ \\
\hline $\begin{array}{l}\text { 6. In the past } 12 \text { months, has your child } \\
\text { used any medicines for allergic disease? }\end{array}$ & $\begin{array}{l}\text { Allergy medication } \\
\text { prescribed }\end{array}$ & 65 & $\begin{array}{c}0.45 \\
(0.08-0.82)\end{array}$ & $\begin{array}{c}0.91 \\
(59 / 65)\end{array}$ & 7 & $0.50 / 0.95$ \\
\hline $\begin{array}{l}\text { 7. Has your child ever had an allergy test, } \\
\text { skin prick test or blood test? }\end{array}$ & Allergy test & 64 & 0.82 & $\begin{array}{c}0.92 \\
(59 / 64)\end{array}$ & 21 & $0.87 / 0.94$ \\
\hline $\begin{array}{l}\text { 8. Has your child ever been treated by } \\
\text { doctor or hospitalised for: Hay fever, } \\
\text { blocked nose or itchy-watery eyes? } \\
\text { Eczema? Urticaria? }\end{array}$ & $\begin{array}{l}\text { Treated by physician } \\
\text { or hospitalised }\end{array}$ & & $\begin{array}{l}0.39 \\
(0.12-0.66)\end{array}$ & $\begin{array}{c}0.80 \\
(51 / 63)\end{array}$ & 9 & $0.50 / 0.88$ \\
\hline $\begin{array}{l}\text { 9. Has your child ever had any of the } \\
\text { following diseases? Common cold? } \\
\text { Ear infection? Bronchitis? RS-virus infection } \\
\text { False croup? Pneumonia? Urinary tract } \\
\text { infection? Gastric flu/tummy bugs? }\end{array}$ & $\ln$ & 66 & $\begin{array}{c}0.53 \\
(0.30-0.76)\end{array}$ & $\begin{array}{c}0.82 \\
(54 / 66)\end{array}$ & 52 & $0.88 / 0.65$ \\
\hline $\begin{array}{l}\text { 10. Are any of the following diseases treated } \\
\text { with penicillin/antibiotics? }\end{array}$ & $\begin{array}{l}\text { Antibiotic treatment } \\
\text { reported in records }\end{array}$ & 53 & $\begin{array}{c}0.81 \\
(0.65-0.97)\end{array}$ & $\begin{array}{c}0.91 \\
(48 / 53)\end{array}$ & 29 & $0.92 / 0.89$ \\
\hline
\end{tabular}

$\mathrm{N}=$ number in analysis, $0<\kappa<0.4$ denotes poor agreement, $0.4<\kappa<0.75$ denotes good agreement, $\kappa>0.75$ denotes excellent agreement $\mathrm{OA}=$ Observed agreement, $\mathrm{n}=$ number of reported yes, $\mathrm{PA}=$ Proportional agreement for yes $/ \mathrm{no}$

and comprehensibility of the questionnaire - led to the rephrasing of some questions. As an example, the concept "infectious disease" was poorly understood and replaced with a list of "some of the following diseases" (see Question 9, Table 2). Overall, there were a few comments and proposals for amendments to the questionnaire.

Agreement between the questionnaire and information in medical records

Ten questions - for which the answers given could be expected to be verified by information in the children's medical records - were selected for reliability testing. If introductory questions were answered by "no", the parents were instructed to go to the next section of the questionnaire leading to different numbers in the analysis (N). The answer "don't know" was excluded from the main analysis. The number of "don't knows" varied between zero and two in the 10 questions.

The results are shown in Table 2. The agreement, assessed as kappa, varied considerably for the different questions. There was excellent agreement for questions reporting actual information like doctor-diagnosed asthma $(\kappa=0.88$, $(0.76$ 1.0)) and whether or not the child had had an allergy test $(\kappa=0.82,(0.66-0.97)$. The proportion of observed agreement for these two questions was also very high, 0.94 and 0.92 , respectively. Proportional agreement was also very high both for "yes" and "no", 0.93 and 0.95 , respectively. 
The agreement was good for questions concerning doctor or hospital treatment for asthma, symptoms of eczema, and medication for allergic and past infections. The agreement for medication for asthma was good, while the agreement was poor for eczema medication $(\kappa=0.33$, [0.11$0.54])$. The agreement was also poor for doctor treatment or hospitalisation for hay fever, eczema and urticaria.

\section{Discussion}

The families lived in areas of mixed socio-economic population and were considered representative for the current age group in Trondheim.

We found excellent agreement for questions reporting factual information such as whether or not the child had had an allergy test or doctor-diagnosed asthma, use of antibiotics, and a history of specific diseases. The potential for classification errors, however, was considerable for questions on treatment for skin rash or eczema, any medicines for allergic disease, and whether the child had been treated by a doctor or had been hospitalised for allergic complaints or diseases.

We chose to test the reliability of the questionnaire by comparing the parents' answers to the information retrieved from medical records. This method has been widely used for both reliability testing and for validating questionnaires in other medical conditions, but to our knowledge, not for the diseases investigated in this study. ${ }^{5-7} \mathrm{~A}$ first prerequisite for a correct classification of reported disease endpoints is that the information given is reliable. Diagnosis of atopic diseases such as asthma, rhinoconjunctivitis, and eczema/dermatitis is based on the medical history, repeated consultations, and knowledge of the child's family and living conditions. As medical records give an overview of all contacts in primary and specialist care over time, diagnosis of atopic diseases is probably best based on such information. Using medical records as a "reference standard" for disease prevalence is, however, only satisfactory provided that the physicians apply diagnostic criteria correctly. Whether the doctor-diagnosed diseases meet the standard criteria for the current diseases, and thereby the validity of the questionnaire, is being studied in a separate endpoint and validity study.

The questionnaire information on doctor-diagnosis of asthma is highly reliable, which is in accordance with findings in the Obstructive Lung Disease in Northern Sweden Study, where the same question was evaluated..$^{8} \mathrm{~A}$ Finnish study on the reliability of a questionnaire for asthma, allergic rhinitis, and conjunctivitis presented similar findings. ${ }^{9}$

A better agreement could be expected for doctor or hospital treatment for asthma. The lack of excellent agreement could be ascribed to a perception that the question was understood as a specific question about hospital admission or hospital treatment only. In four questionnaire responses the parents reported no doctor treatment or hospitalisation for asthma, but the records actually provided information on multiple primary care consultations for asthma. No hospitalisation was confirmed. Rephrasing the question would probably increase the agreement level.

A higher agreement for the question on medical treatment for asthma could also be expected. A higher proportional agreement for "yes" indicates that a positive response is more reliable than a negative response. From the findings in the medical records, our interpretation was that some parents seemed to misapprehend, indicating that asthma medication was perceived as an anti-allergic medicine.

The kappa value for the question on eczema medication was low. However, observed agreement and proportional agreement for "no" was high. This paradox is discussed in detail by Feinstein and cicchetti. ${ }^{10}$ This question is very specific for detecting children who are not being treated for eczema. One interpretation could be that many parents treat their children's eczema themselves with over-the-counter medication, and do not consult their physician for this problem.

A low kappa value for use of anti-allergic medication in the past year was found. A high observed agreement, a relatively low proportional agreement for "yes", and very high proportional agreement for "no" was observed. The paradox of high agreement and low kappa is in this case probably due to prevalence bias, with only five positive responders. ${ }^{11}$ As a consequence, this question is unsuitable for detecting children treated for allergy, but its specificity for identifying children not treated for allergy is excellent.

There was poor agreement with a low report on doctortreated or hospitalisation for hay fever, eczema and urticaria. Observed agreement for this question, and proportional agreement for "no", was high. Together with a relatively low proportional agreement for "yes" this could be due to a perception that the question was exclusively about hospital admission or hospital treatment. Consequently, a more precise question on contact with health services due to allergic conditions is required. For questions 5, 6 and 8, therefore, a positive answer is prone to misclassification and thereby unreliable. A negative answer, however, contains less classification error, and is in this respect more trustworthy. All three should be specified in more detail and retested.

The study population consisted of two groups of children, both randomly selected from the control cohort of PACT. A possible bias might be introduced by the selection of the second group, stratified by positive answers to having asthma or allergic disease. An increased awareness on atopic disease 
among these parents may affect the reliability of the answers given. For the disease endpoints 'asthma' and 'eczema', however, they would be representative as the awareness of diagnostic information would be the same for corresponding groups of parents. The method may yet increase the reliability for some of the other questions. However, this method was chosen as a manageable way to collect enough data from different medical records.

\section{Conclusions}

A newly developed questionnaire for use in the PACT study for estimating the prevalence of asthma, rhinoconjunctivitis, and eczema/dermatitis among children aged two to six years old was tested for reliability. The questionnaire was adapted from the ISAAC protocol, was modified to suit the age of the study population, and contained questions on symptoms, investigation, diagnosis and treatment for atopic disease. We found that the agreement between parent-reported information and the information obtained by examining medical records was good to excellent for the questions estimating prevalence of disease. The questionnaire may possibly underestimate the use of anti-allergic medication, as well as doctor treatment for allergic disease. No question overestimated the prevalence of atopic symptoms or medication use.

It appears to be important to differentiate between the information based on parents' opinions and experience, and the information they have shared with and/or received from the health services on any level. Still, the deficiencies in communication and in the understanding between parents and medical staff, and the shortcomings in updating the medical records, could impair any agreement. Knowledge of the agreement is, howeven, important as inferences of research results should include the potential for misclassification.

\section{Conflict of interest declaration}

None declared.

\section{Funding statement}

Funding for this study was obtained from the Norwegian Department of Health and Social Affairs, 1997-2003. The control cohort was funded by AstraZeneca Norge, 2000-2001. A university scholarship from NTNU and a scholarship from the Norwegian Research Council 1999-2003 funded the research fellows. Grants were also obtained from the Norwegian Medical Association and SINTEF Unimed 1999.

\section{References}

1. Jenssen J, Storrø O, Øien T, Johnsen R. Prevention of allergy among children in Trondheim. Allergi i praksis 2001;4:34-8.

2. Anonymous. Worldwide variation in prevalence of symptoms of asthma, allergic rhinoconjunctivitis, and atopic eczema: ISAAC. The International Study of Asthma and Allergies in Childhood (ISAAC) Steering Committee. Lancet 1998; 351(9111):1225-32.

3. Gjorup $T$, Jensen AM. The kappa coefficient - a goal for evaluating the reproducibility of nominal and ordinary data. Nord Med 1986;101(3):90-4.

4. Cicchetti DV, Feinstein AR. High agreement but low kappa: II. Resolving the paradoxes. J Clin Epidemiol 1990;43(6):551-8.

5. Daly KA, Lindgren B, Giebink GS. Validity of parental report of a child's medical history in otitis media research. Am J Epidemiol 1994;139(11):1116-21.

6. Haapanen N, Miilunpal0 S, Pasanen M, Oja P, Vuori I. Agreement between questionnaire data and medical records of chronic diseases in middle-aged and elderly Finnish men and women. Am.J Epidemiol 1997;145(8):762-9.

7. Midthjêll $\widehat{K}$, Holmen J, Bjorndal $A$, Lund-Larsen $G$. Is questionnaire information valid in the study of a chronic disease such as diabetes? The Nord-Trondelag diabetes study: J Epidemiol Community Health 1992;46(5):537-42.

8. Ronmark E, Jonsson E, Platts-Mills T, Lundback B. Different pattern of risk factors for atopic and nonatopic asthma among children - report from the Obstructive Lung Disease in Northern Sweden Study. Allergy 1999;54(9):92635.

9. Kilpelainen $M$, Terho EO, Helenius $H$, Koskenvuo $M$. Validation of a new questionnaire on asthma, allergic rhinitis, and conjunctivitis in young adults. Allergy 2001;56(5):377-84.

10. Feinstein AR, Cicchetti DV. High agreement but low kappa: I. The problems of two paradoxes. J Clin Epidemiol 1990;43(6):543-9.

11. Byrt T, Bishop J, Carlin JB. Bias, prevalence and kappa. J Clin Epidemiol 1993; 46(5):423-9. 